\title{
Electron Capture Dissociation of Complexes of Diacylglycerophosphocholine and Divalent Metal Ions: Competition Between Charge Reduction and Radical Induced Phospholipid Fragmentation
}

\author{
Patrick F. James, ${ }^{\mathrm{a}, \mathrm{c}}$ Matthew A. Perugini, ${ }^{\mathrm{a}, \mathrm{c}}$ and Richard A. J. O'Hair ${ }^{\mathrm{b}, \mathrm{d}}$ \\ a Department of Biochemistry and Molecular Biology, University of Melbourne, Parkville, Victoria, Australia \\ ${ }^{\mathrm{b}}$ School of Chemistry, University of Melbourne, Parkville, Victoria, Australia \\ ${ }^{\mathrm{c}}$ Bio21 Molecular Science and Biotechnology Institute, University of Melbourne, Parkville, Victoria, Australia \\ d Australian Research Council Centre of Excellence for Free Radical Chemistry and Biotechnology, School of \\ Chemistry, Bio21 Molecular Science and Biotechnology Institute, University of Melbourne, Parkville, Victoria, \\ Australia
}

Divalent metal complexes of phosphocholines, $\left[\operatorname{Metal}^{\mathrm{II}}(\mathrm{L})_{n}\right]^{2+}\left(\right.$ where Metal $=\mathrm{Cu}^{2+}, \mathrm{Co}^{2+}$, $\mathrm{Mg}^{2+}$, and $\mathrm{Ca}^{2+}, \mathrm{L}=1,2$-dihexanoyl-sn-glycero-3-phosphocholine [6:0/6:0GPCho] and 1-palmitoyl-2-oleoyl-sn-glycero-3-phosphocholine [16:0/18:1GPCho] and $n=2-5)$, were formed upon electrospray ionization mass spectrometry (ESI/MS) of $8 \mathrm{mM}$ solution of phosphocholine (L) with $4 \mathrm{mM}$ metal salt (Metal). The electron capture dissociation (ECD) reactions of these $\left[\mathrm{Metal}^{\mathrm{II}}(\mathrm{L})_{n}\right]^{2+}$ complexes were examined via Fourier-transform ioncyclotron resonance mass spectrometry. A rich and complex chemistry was observed, including charge reduction and fragmentation involving losses of a methyl radical, trimethylamine, and the acyl chains. The predominant reaction channel was dependent on the size $(n)$ of the complex, the metal and ligand used, and the size of the acyl chain. Thus charge reduction dominates the ECD spectra of the larger phosphocholine, 16:0/18:1GPCho, but is largely absent in the smaller 6:0/6:0GPCho. For complexes of 16:0/18:1GPCho, $n=4-5$, fragmentation from the head group mainly occurs via loss of the methyl radical and trimethylamine. At $n=3$, the relative abundance of fragments due to loss of acyl chain radicals increases. The abundances of ions arising from these radical losses increase further for the $n=$ 2 complexes, thereby providing information on the composition and position of the $16: 0$ and 18:1 acyl groups. Thus ECD of metal complexes provides structurally useful information on the phosphocholine, including the nature of the head group, the acyl chains, and the positions of the acyl chains. (J Am Soc Mass Spectrom 2008, 19, 978-986) (C) 2008 American Society for Mass Spectrometry

$\mathrm{M}$ any previous studies have highlighted the promise of metal ions as reagents in analytical and bioanalytical chemistry [1-3]. As part of a series of studies on the use of mass spectrometry-based approaches to examine lipid-lipid interactions [4], we have become interested in understanding how metal ions may influence fragmentation chemistry. Although the fragmentation of phosphocholines has been extensively studied in the past, with reviews [5] and fragmentation mechanisms elucidated for singly charged phosphocholine $\left(\mathrm{H}^{+}, \mathrm{Li}^{+}, \mathrm{Na}^{+}\right)$[6], few studies have examined the fragmentation of phosphocholines in the presence of divalent cations. Past studies include the

Address reprint requests to Dr. Richard A. J. O'Hair, University of Melbourne, School of Chemistry, Bio21 Molecular Science and Biotechnology Institute, Parkville, Victoria 3010, Australia. E-mail: rohair@unimelb.edu.au This article is Part 57 of the series "Gas Phase Ion Chemistry of Biomolecules." collision-induced dissociation (CID) of (i) $\left[\mathrm{Metal}(\mathrm{L})_{n}\right]^{2+}$ $($ Metal $=\mathrm{Li}, \mathrm{K}, \mathrm{Sc}, \mathrm{Va}, \mathrm{Cr}, \mathrm{Fe}, \mathrm{Mn}, \mathrm{St}, \mathrm{Ni}, \mathrm{Co}, \mathrm{Cu}, \mathrm{Zn}$ ) of $\mathrm{L}=$ glycerophosphoethanolamines, glycerophosphoglycerols, and glycerophosphoserines [7]; (ii) of $\left[\mathrm{Cu}^{\mathrm{II}}(\mathrm{L})_{n}\right]^{2+}$ complexes of $\mathrm{L}=1$,2-dihexanoyl-sn-glycero-3-phosphocholine ( $\mathrm{L}=6: 0 / 6: 0 \mathrm{GPCho}$ ) [8]; and (iii) of $\left[\text { Metal }^{\mathrm{II}}(\mathrm{L})_{n}\right]^{2+}$ complexes of $\mathrm{L}=1$-palmitoyl-2oleoyl-sn-glycero-3-phosphocholine, which allows distinction of acyl chains [9]. We were thus intrigued by the possibility of using electron capture dissociation (ECD) on divalent metal complexes of phospholipids to gain additional structural information, since recent studies suggest that divalent metal ions not only can direct the fragmentation of peptides under conditions of ECD [10-13], but also act as charge tags to allow the use of ECD on other biomolecules that may not undergo multiple protonation under electrospray ionization (ESI) conditions [13]. 


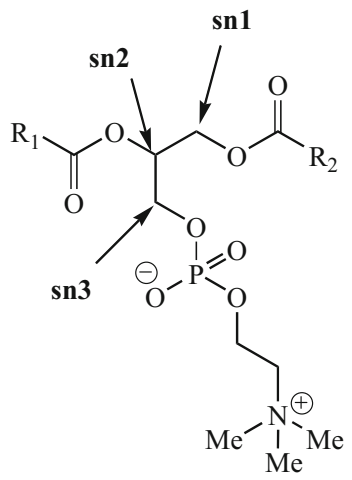

Scheme 1

Here we present the results of ECD experiments on $\left[\mathrm{Metal}^{\mathrm{II}}(\mathrm{L})_{n}\right]^{2+}$ complexes of model phosphocholines (where Metal $=\mathrm{Ca}^{2+}, \mathrm{Mg}^{2+}, \mathrm{Co}^{2+}$, or $\mathrm{Cu}^{2+}$ and $\mathrm{L}=$ 1-palmitoyl-2-oleoyl-sn-glycero-3-phosphocholine or 1,2-dihexanoyl-sn-glycero-3-phosphocholine; Scheme 1). These different phospholipids were chosen because the different masses of their acyl chains should allow ready mass assignments of ECD fragments. During the course of this work, we became aware of related electron-transfer dissociation (ETD) reactions of $[\mathrm{M}+$ $2 \mathrm{Na}]^{2+}$ ions of phosphocholines with the azobenzene radical anion, which resulted in several unusual fragmentation channels including: formation of the reduced species, $[\mathrm{M}+2 \mathrm{Na}]^{+\cdot}$ (eq 1$)$; loss of a sodium atom (eq 2); loss of trimethylamine (eq 3) and a methyl radical (eq 4) from the head group; and cleavage of the acyl bonds at the sn1 and sn2 positions [14].

$$
\begin{aligned}
& {[\mathrm{M}+2 \mathrm{Na}]^{2+}+\mathrm{PhNNPh}^{-} \rightarrow[\mathrm{M}+2 \mathrm{Na}]^{+}+\mathrm{PhNNPh}} \\
& \rightarrow[\mathrm{M}+\mathrm{Na}]^{+}+\mathrm{PhNNPh}+\mathrm{Na} \\
& \rightarrow\left[\mathrm{M}+2 \mathrm{Na}-\mathrm{NMe}_{3}\right]^{+}+\mathrm{PhNNPh}+\mathrm{NMe}_{3} \\
& \rightarrow[\mathrm{M}+2 \mathrm{Na}-\mathrm{Me}]^{+}+\mathrm{PhNNPh}+\mathrm{Me}
\end{aligned}
$$

\section{Experimental}

\section{Materials}

The following lipid samples were obtained from Avanti Polar Lipids (Alabaster, AL, USA) and used without further purification: 1,2-dihexanoyl-sn-glycero-3-phosphocholine and 1-palmitoyl-2-oleoyl-sn-glycero-3-phosphocholine. All other chemicals were obtained from Sigma-Aldrich (Sydney, Australia) and used as received.

\section{Linear Ion Trap-Fourier Transform Ion-Cyclotron Resonance Mass Spectrometry (FT-ICR/MS) Experiments}

All experiments were carried out using an $8 \mathrm{mM}$ solution of either 6:0/6:0GPCho or 16:0/18:1GPCho on a Finnigan-MAT LTQ-Fourier transform mass spectrometry (FTMS) instrument equipped with ESI and factory fitted with the ECD cathode. The relevant complexes were formed by adding $\mathrm{CaCl}_{2}, \mathrm{MgCl}_{2}, \mathrm{CoCl}_{2}$, and $\mathrm{CuCl}_{2}$ to the lipid solution to a final concentration of $4 \mathrm{mM}$. The samples were introduced to the mass spectrometer at $3.0 \mu \mathrm{L} / \mathrm{min}$ via electrospray ionization. Typical ESI conditions used were: spray voltage, $5.0 \mathrm{kV}$; capillary temperature, $200{ }^{\circ} \mathrm{C}$; nitrogen sheath pressure, $40 \mathrm{psi}$; and capillary voltage/tube lens offset, $0 \mathrm{~V}$. The injection time was set using the AGC function (set at 1 $\times 10^{5}$ ions for the ion trap and $5 \times 10^{5}$ ions for the FT-ICR cell including ECD experiments). Ions of interest were selected in the linear ion trap, with either a 5 or 10 Th window and transmitted to the FT-ICR cell for further analysis. ECD was carried out by subjecting the trapped ions to the following typical conditions: -9.2 $\mathrm{eV}, 5 \mathrm{~ms}$ delay, and activation time $50 \mathrm{~ms}$.

To validate the proposed fragmentation pathways, we used the high mass accuracy of the FT-ICR cell to compare the observed masses with those expected for the proposed fragmentation pathways (Supplemental Table S1, which can be found in the electronic version of this article). To compare the reproducibility of the relative yields of the different fragment ions in the ECD spectra of the [Metal ${ }^{\mathrm{II}}$ $\left.(\mathrm{L})_{n}\right]^{2+}$ complexes, ECD spectra were measured for all complexes where $\mathrm{L}=$ 6:0/6:0GPCho on three different occasions and the data (a total of 48 ECD spectra) were analyzed. The maximum deviation observed for the relative ion abundances was $1.6 \%$ for the spectra collected using copper as the metal center, demonstrating that the spectra are highly reproducible.

\section{Results and Discussion}

\section{Overview of ECD Fragmentation Chemistry of $\left[\operatorname{Metal}^{I I}(L)_{n}\right]^{2+}$ Complexes}

ESI/MS of solutions containing divalent metal salts and phosphocholines yield a range of $\left[\operatorname{Metal}^{\mathrm{II}}(\mathrm{L})_{n}\right]^{2+}$ complexes, where Metal $=\mathrm{Cu}^{2+}, \mathrm{Co}^{2+}, \mathrm{Mg}^{2+}$, and $\mathrm{Ca}^{2+}$ and $n=2-8$, in addition to protonated phosphocholine and its proton bound clusters (Supplemental Figure S1). Previous work has shown that the presence of the larger clusters of phosphocholines are concentration dependent and can be dissociated via in-source CID by increasing the tube lens voltage [4]. The presence of a divalent metal cation provides an opportunity to examine the electron capture dissociation reactions of phosphocholines. Figure 1 and Scheme 2 highlight the entire range of primary reactions observed in the ECD spectra of the $\left[\mathrm{Metal}^{\mathrm{II}}(\mathrm{L})_{n}\right]^{2+}$ complexes. Some charge-reduced complexes are observed, as well as a range of fragments ions that arise from dissociation of this reduced complex. The types of fragmentation reactions observed include loss of: the phosphocholine ligand, L (Figure 1a, $\mathrm{m} / \mathrm{z} 969$ and eq 5 of Scheme 2); $\mathrm{Me}$ (eq 6 of Scheme 2); $\mathrm{Me}_{3} \mathrm{~N}$ (eq 7 of Scheme 2); and loss of the acyl chain (eq 8 of Scheme 2). The last three reactions are common to 


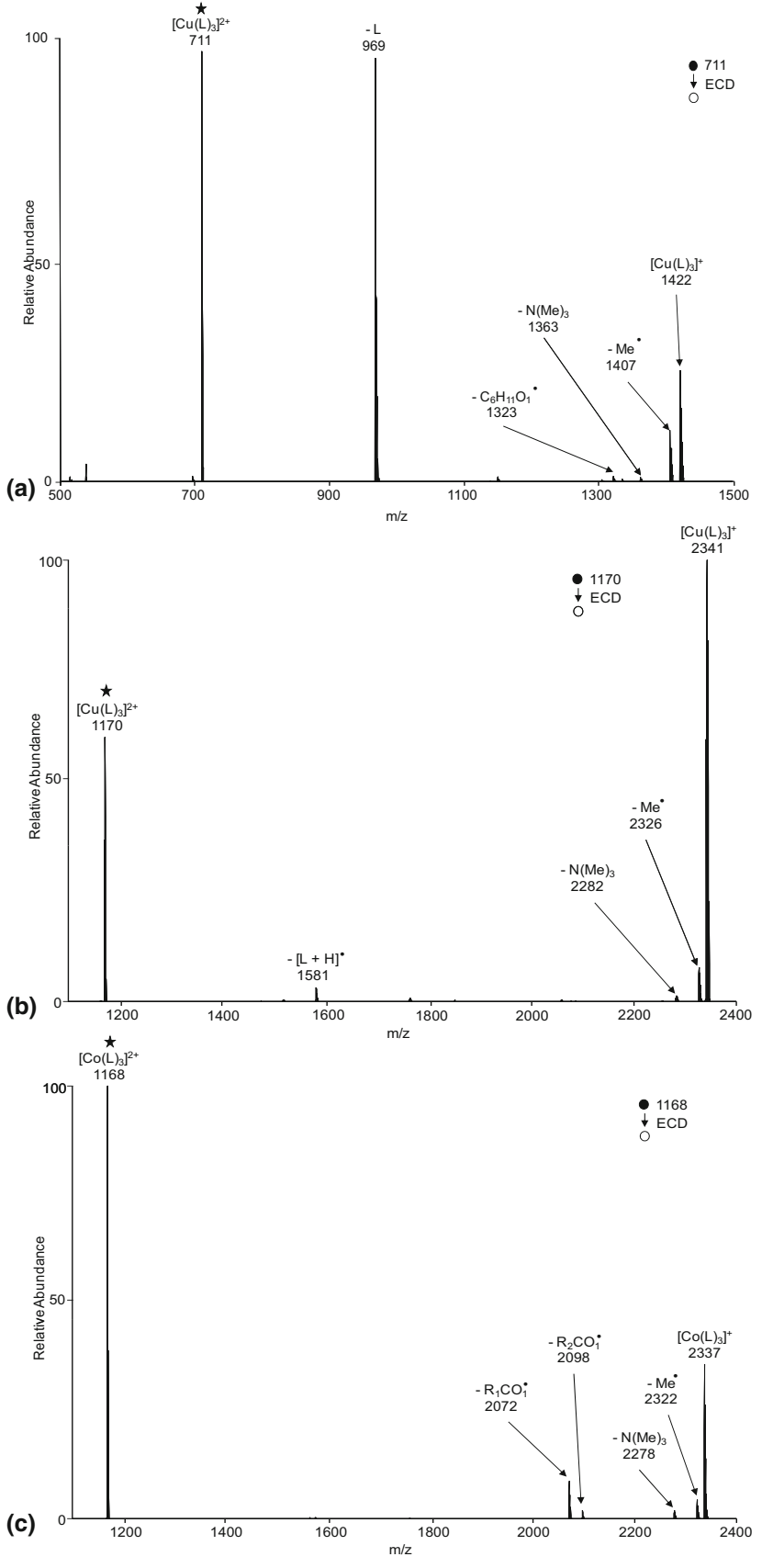

Figure 1. LTQ ESI ECD spectra (activation time of $50 \mathrm{~ms}$ ) of different $\left[\mathrm{Metal}^{\mathrm{II}}(\mathrm{L})_{3}\right]^{2+}$ complexes: $($ a) Metal $=\mathrm{Cu}, \mathrm{L}=6: 0 / 6$ : 0GPCho; (b) Metal $=\mathrm{Cu}, \mathrm{L}=16: 0 / 18: 1 \mathrm{GPCho}$; $(\mathbf{c})$ Metal $=\mathrm{Co}, \mathrm{L}$ $=16: 0 / 18: 1 \mathrm{GPCh}$. The mass selected precursor ion is designated by $a *$.

the ECD spectra of all the metal complexes studied, although their relative abundances vary significantly. Note also that the ECD losses of $\mathrm{Me}$ and $\mathrm{Me}_{3} \mathrm{~N}$ and related to those observed in the ETD reactions of the [M $+2 \mathrm{Na}]^{2+}$ ions of phosphocholines (eqs 3 and 4) [22]. A final, uncommon fragmentation channel observed involves loss of [L + H] (Figure 1b, m/z 1581 and eq 9 of Scheme 2).

Before examining the role of the individual components of the complexes in promoting the different

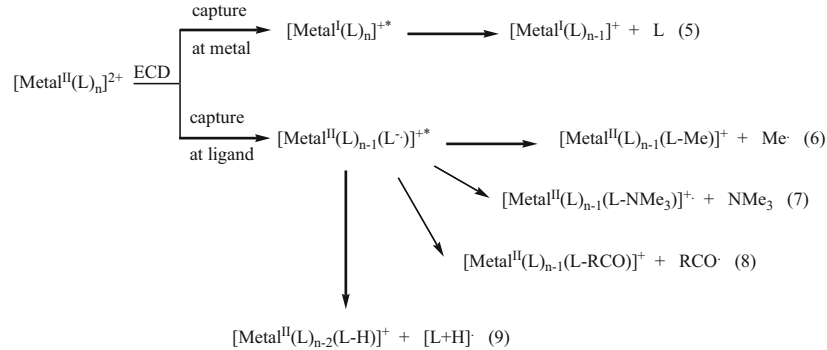

Scheme 2

fragmentation reactions in Scheme 2, a key question concerning the ECD process of $\left[\mathrm{Metal}^{\mathrm{II}}(\mathrm{L})_{n}\right]^{2+}$ complexes is: Where does reduction occur and how might this give rise to the fragmentation reactions observed? In principle, reduction can occur either at the metal or at various sites on the ligand and these could help trigger the different types of fragmentation reactions observed (Scheme 2). Unfortunately, the size of these complexes and the challenges of modeling transition-metal complexes preclude carrying out DFT (density functional theory) calculations to gain mechanistic insights into these ECD processes. Instead, we will discuss potential structures of reduced species and their roles in the observed ECD reactions by making comparisons to related systems published in the literature. Reduction at the metal yields species A. Reduction at the quaternary nitrogen of the phosphocholine ligand yields the hypervalent radical $\mathbf{B}$, a species that is expected to readily fragment via loss of $\mathrm{Me}$ (eq 6 of Scheme 2) and $\mathrm{Me}_{3} \mathrm{~N}$ (eq 7 of Scheme 2) based on the neutralization-reionization mass spectrometry (NRMS) studies of Beranova and Wesdemiotis on related hypervalent radicals [15]. In contrast, reduction at either of the carbonyl groups of the phosphocholine ligand would yield the ketyl radical anions $\mathbf{C} \mathbf{1}$ and $\mathbf{C} 2$. Not only are these species related to the superbase mechanism for ECD [16, 17], but based on previous gas-phase [18] and condensed-phase [19] studies on ketyl radical anions, these would be expected to fragment via $\alpha$-cleavage reactions to yield the products shown in eq 8 of Scheme 2.

We now use the notion of capture at different sites (species A-C) to help rationalize the types of reactions observed (Scheme 2) in specific ECD spectra of $\left[\operatorname{Metal}^{\mathrm{II}}(\mathrm{L})_{n}\right]^{2+}$ complexes. The ECD spectrum of the $\left[\mathrm{Cu}^{\mathrm{II}}(\mathrm{L})_{3}\right]^{2+}$ complex of 6:0/6:0GPCho (Figure 1a) represents an example of how capture of the electron at the metal center can result in a vibrationally excited-state complex, which then fragments via loss of a neutral phosphocholine ligand (to give $\mathrm{m} / \mathrm{z}$ 969). It is worth noting that the vibrational excitation of independently generated $\left[\mathrm{Cu}^{\mathrm{I}}(\mathrm{L})_{3}\right]^{+}$complex also results in fragmentation via phosphocholine ligand loss (for the CID spectrum of the $\left[\mathrm{Cu}^{\mathrm{I}}(\mathrm{L})_{3}\right]^{+}$complex of 6:0/6:0GPCho see Supplemental Figure S2).

In contrast, capture of the electron at the ligand yields a new radical species, which can fragment following initial capture. As noted earlier, choline, with its 


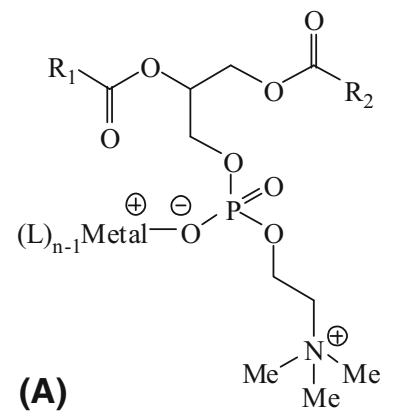

ternary nitrogen can yield structure $\mathbf{B}$, which in turn can fragment via loss of a methyl radical (eq 6, Scheme 2: $m / z$ 2326, Figure $1 b ; m / z$ 2322, Figure 1c), and is related to losses observed in NRMS experiments on alkyl ammonium ions [15]. Indeed, Syrstad and Tureček [16] suggest that the presence of a fixed charge on the nitrogen enhances the loss of a methyl radical. Alternatively, B can fragment via loss of trimethylamine (eq 10), which leaves a carbon-centered radical. The peaks arising from $\mathrm{Me}_{3} \mathrm{~N}$ loss are observed at $\mathrm{m} / \mathrm{z} 2282$ in Figure $1 \mathrm{~b}$ for the $\left[\mathrm{Cu}(\mathrm{L})_{3}\right]^{2+}$ complex of 16:0/18:1GPCho and $m / z 2278$ in Figure $1 \mathrm{c}$ for the $\left[\mathrm{Ca}(\mathrm{L})_{3}\right]^{2+}$ complex of 16:0/18:1GPCho. Capture of the electron at either of the two acyl groups in 16:0/18:1GPCho yields the structures $\mathbf{C} \mathbf{1}$ and $\mathbf{C} 2$ (for capture at the sn1 and sn2 positions, respectively). Fragmentation of the resultant ketyl radical anions proceeds via $\alpha$-cleavage (eq 8), with the losses at $m / z 2098$ for loss of the 16:0 acyl group and $\mathrm{m} / \mathrm{z} 2072$ for the 18:1 acyl group (Figure 1c). In addition to revealing the identity of the two acyl groups, this fragmentation opens the possibility of identifying the sn1 or sn2 position of the acyl group. Although Figure 1 illustrates the classes of reactions that can occur for different $\left[\mathrm{Metal}^{\mathrm{II}}(\mathrm{L})_{n}\right]^{2+}$ complexes, it raises another

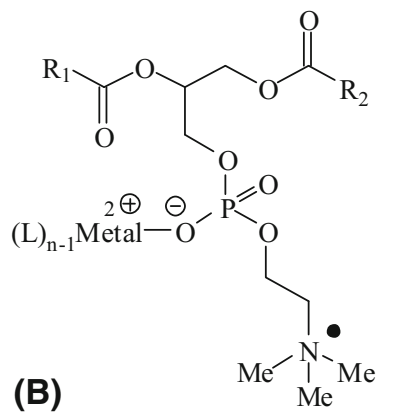

important question: What effect do the nature of the ligand, the number of ligands, and the type of metal play in the types of fragmentations observed for a specific complex? This is explored further below.

\section{Role of the Ligand}

By studying two different phospholipid ligands (6:0/6: 0GPCho and 16:0/18:1GPCho), we are able to establish

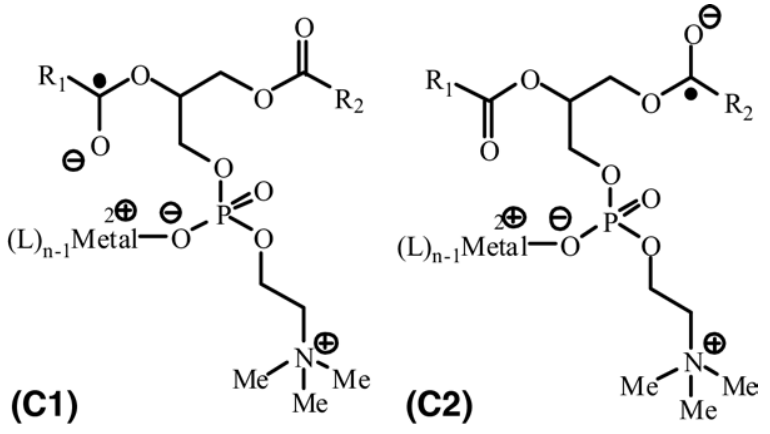

how changing the size of the acyl groups and thus the overall size of the ligand influences the ECD mass spectra of $\left[\mathrm{Metal}^{\mathrm{II}}(\mathrm{L})_{n}\right]^{2+}$ complexes for the same value of $n$. Both sets of ECD spectra were collected and analyzed in a similar manner. A comparison of the ECD spectra of the $\left[\mathrm{Cu}^{\mathrm{II}}(\mathrm{L})_{3}\right]^{2+}$ complexes (Figure 1a and b) shows that whereas similar ligand fragmentation reactions such as $\mathrm{Me}$ and $\mathrm{Me}_{3} \mathrm{~N}$ loss are observed, the main role for the ligand appears to be to stabilize the chargereduced metal complex. Thus the charge-reduced complex of the smaller ligand ( $\mathrm{L}=6: 0 / 6: 0 \mathrm{GPCho}$ ) undergoes significant fragmentation via neutral loss (eq 5, Figure 1a). In contrast, the complex with the larger ligand $(\mathrm{L}=$ 16:0/18:1GPCho), which has more vibrational degrees of freedom, gives a higher relative yield of the chargereduced complex. A similar capacity for the larger 16:0/ 18:1GPCho ligand to stabilize the charge-reduced complex is observed in the ECD spectra for all the other $\mathrm{Cu}$ complexes (compare Supplemental Figures S3 and S4). Alternatively, the higher yield of the charge-reduced complex may arise from stronger van der Waals contacts between the larger phospholipids, which are expected to be less pronounced for the short-chain phospholipid.

The differences in the ECD spectra of the $\left[\operatorname{Metal}^{\mathrm{II}}(\mathrm{L})_{n}\right]^{2+}$ complexes is even more dramatic for the other metals, where reduced metal complexes are essentially all decomposed when $\mathrm{L}=$ 6:0/6:0GPCho (Supplemental Figure S5 for Metal = Co; Supplemental Figure S6 for Metal = Mg; Supplemental Figure S7 for Metal $=\mathrm{Ca}$ ) but are observed to some extent when $\mathrm{L}=$ 16:0/18:1GPCho (Supplemental Figure S8 for Metal = Co; Figure 2 for Metal = Mg; Supplemental Figure S9 for Metal $=\mathrm{Ca})$. Although each spectrum cannot be discussed individually in detail, it is interesting to compare the ECD spectra of $\left[\mathrm{Ca}^{\mathrm{II}}(\mathrm{L})_{4}\right]^{2+}$ when $\mathrm{L}=$ 6:0/6:0GPCho (Supplemental Figure S7B) and L = 16:0/18:1GPCho (Supplemental Figure S9B). First, since both acyl groups have the same chain length in 6:0/6: 0GPCho, it is not possible to determine whether RCO loss (eq 8) occurs from the sn1 or sn2 position. This is in contrast to the case where $\mathrm{L}=16: 0 / 18: 1 \mathrm{GPCh}$, where both losses can be distinguished (Supplemental Figure S9B) and are observed with nearly equal abundances. Also noteworthy is that more secondary fragmentation corresponding to the combined losses of $\mathrm{NMe}_{3}$ and $\mathrm{RCO}_{2} \cdot($ eq 10) is observed when $\mathrm{L}=6: 0 / 6: 0 \mathrm{GPCho}$. The 

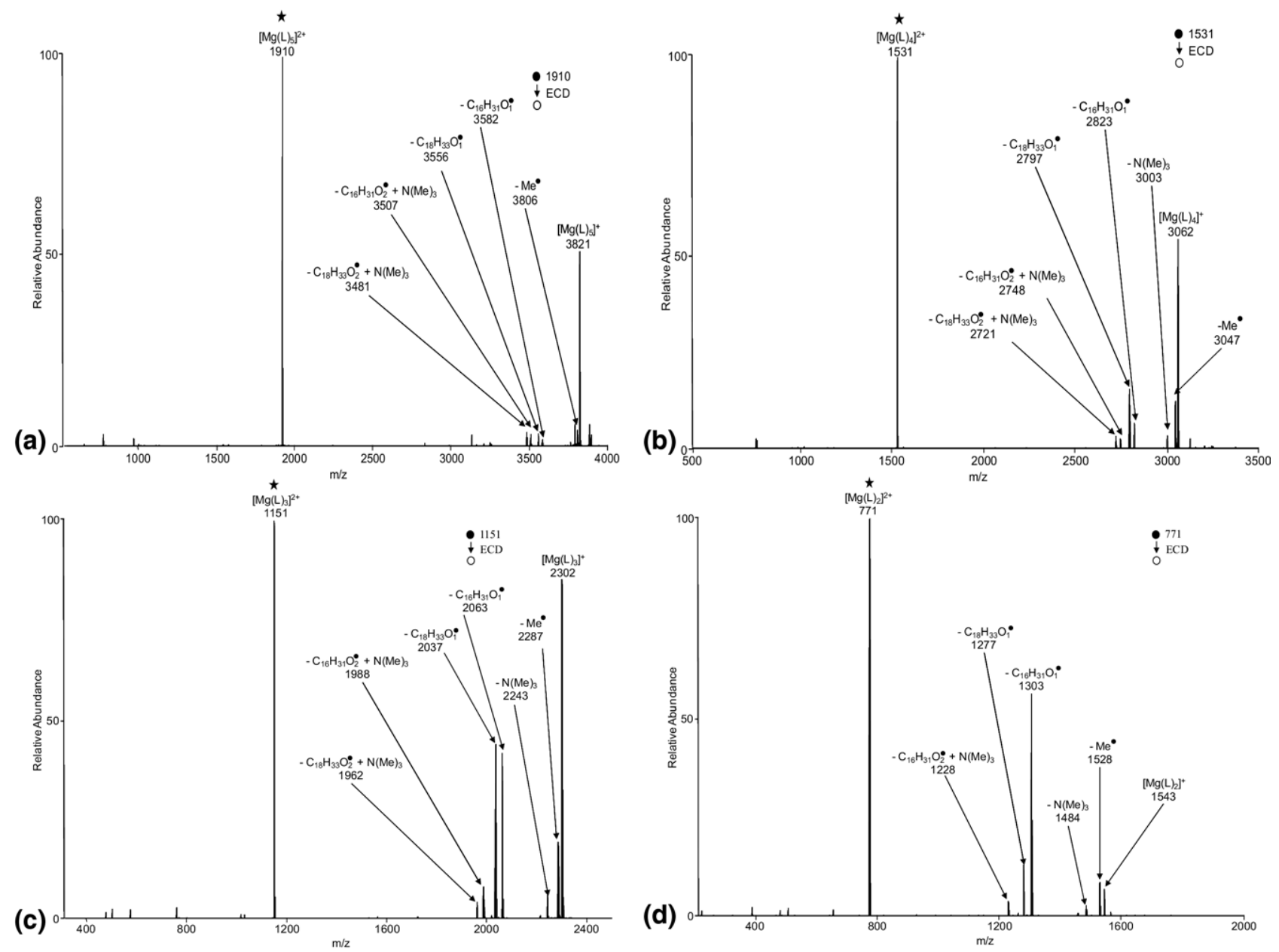

Figure 2. LTQ ESI ECD spectra (activation time of $50 \mathrm{~ms}$ ) of the magnesium complexes $\left[\mathrm{Mg}^{\mathrm{II}}(\mathrm{L})_{n}\right]^{2+}$, $\mathrm{L}=16: 0 / 18: 1 \mathrm{GPCho:}(\mathbf{a}) n=5 ;$ (b) $n=4$; (c) $n=3$; (d) $n=2$. The mass selected precursor ion is designated by an *.

resultant ligand fragmentation product ions (eq 10) are even-electron species that may correspond to the coordinated cyclic phosphates D1 and D2.

$$
\begin{aligned}
& {\left[\operatorname{Metal}^{\mathrm{II}}(\mathrm{L})_{\mathrm{n}}\right]^{2+}+\mathrm{e}^{-} \rightarrow\left[\operatorname { M e t a l } ^ { \mathrm { II } } ( \mathrm { L } ) _ { \mathrm { n } - 1 } \left(L-\left(\mathrm{NMe}_{3}\right.\right.\right.} \\
& \left.\left.\left.+\mathrm{RCO}_{2}\right)\right)\right]^{+}+\mathrm{NMe}_{3}+\mathrm{RCO}_{2}
\end{aligned}
$$

Since the 16:0/18:1GPCho ligand allows distinction of losses involving the different acyl groups at the sn1 and sn2 positions, we focus our discussions on this ligand in the remaining sections, which describe the role of the number of ligands and the metal used.

\section{Role of the Number of Ligands $(n=2-5)$}

Because of the size of the $\left[\operatorname{Metal}^{\mathrm{II}}(\mathrm{L})_{n}\right]^{2+}(\mathrm{L}=16: 0 / 18$ : 1GPCho) complexes, we chose to focus on the complexes where $n=2-5$, to allow accurate mass assignments in the FTMS cell. The ECD spectra of four common divalent metals (Metal $=\mathrm{Ca}^{2+}, \mathrm{Mg}^{2+}, \mathrm{Cu}^{2+}$, and $\mathrm{Co}^{2+}$ ) were examined. Spectra for magnesium complexes are shown in Figure 2, whereas the related
ECD spectra for the remaining three metals are given in the supplementary materials (copper: Supplemental Figure S4; cobalt: Supplemental Figure S8; calcium: Supplemental Figure S9). The major fragment ion observed in the ECD of $\left[\mathrm{Mg}^{\mathrm{II}}(\mathrm{L})_{5}\right]^{2+}$ is the charge-reduced species at $\mathrm{m} / \mathrm{z} 3821$ (Figure 2a). As mentioned earlier, because of the size of the ligand, and the large number of ligands in the complex, the recombination energy could be dissipated over more vibrational degrees of freedom or, alternatively, the complex may be stabilized by noncovalent ligand interactions. Further fragment ions observed include those arising from loss of a methyl radical (eq 6) at $\mathrm{m} / \mathrm{z} 3806$ and loss of the acyl chains (eq 8) at $\mathrm{m} / \mathrm{z} 3582$ and $\mathrm{m} / \mathrm{z}$ 3556. However, compared to the charge-reduced complex, these structurally informative ions are less than $10 \%$ relative intensity. This result indicates that the $\left[\mathrm{Mg}^{\mathrm{II}}(\mathrm{L})_{5}\right]^{2+}$ complex is resistant to dissociation upon reduction.

Similarly, the $\left[\mathrm{Mg}^{\mathrm{II}}(\mathrm{L})_{4}\right]^{2+}$ complex displays little fragmentation upon ECD activation (Figure 2b). Although the charge-reduced product ion at $\mathrm{m} / \mathrm{z} 3062$ is observed at $50 \%$ intensity, the other peaks correspond- 


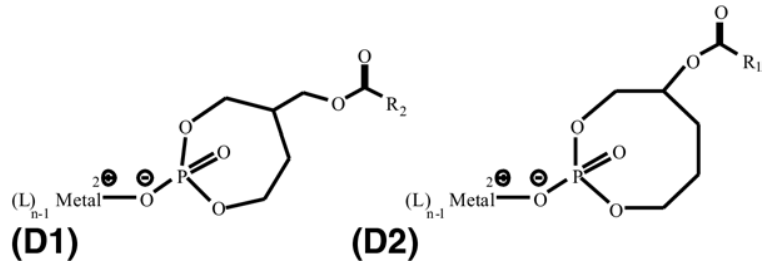

ing to the fragmentation reactions shown in eqs 6-8 are no more than $20 \%$ intensity. When the size of the complex reaches $\left[\mathrm{Mg}^{\mathrm{II}}(\mathrm{L})_{2}\right]^{2+}$, the relative abundances of the fragment ions surpass that of the charge-reduced complex (Figure 2d).

Apart from the relative yields of the charge-reduced complex to the fragment ions, Figure 2 reveals some interesting differences in the relative abundances of the fragment ions arising from the losses of the sn1 and sn2 acyl groups. For example, for the $\left[\mathrm{Mg}^{\mathrm{II}}(\mathrm{L})_{4}\right]^{2+}$ complex, the relative abundance of ion at $\mathrm{m} / \mathrm{z} 2823$ arising from the loss of the 16:0 acyl group is smaller than that of ion at $m / z 2797$ because of loss of the 18:1 acyl group. In contrast, these orders are reversed for the $\left[\mathrm{Mg}^{\mathrm{II}}(\mathrm{L})_{2}\right]^{2+}$ complex, where the loss of the 16:0 acyl group dominates. Although the exact origins of these differences are unclear, we speculate that they may be attributed to subtle changes in the coordination environments at the metal centers. Thus loss of the acyl chain yields an alkoxide ion. These might coordinate to give the structures E1 and E2, which differ in their ring sizes.

\section{Role of the Metal}

Previous studies by Liu et al. [13] and Liang et al. [14] have shown that the metal center is capable of modulating the fragmentation of peptides and lipids under reducing conditions. Thus, we were interested in examining the effect of altering the metal center upon the ECD spectra of both 6:0/6:0GPCho and 16:0/18:1GPCho. To compare the effect of the metal center on the pathways described earlier, we compared the relative abundance of each of the primary fragmentation pathways (eqs 6-8 of Scheme 2) to the sum of all pathways (eq 11) using the data from Figure 2 and Supplemental Figures S3-S9. The resultant plots, shown in Figures 3 and 4, are grouped by metal and ordered from the $\left[\mathrm{Metal}^{\mathrm{II}}(\mathrm{L})_{5}\right]^{2+}$ complex through the $\left[\mathrm{Metal}^{\mathrm{II}}(\mathrm{L})_{2}\right]^{2+}$ complex. To evaluate the reproducibility of these results, experiments with 6:0/6:0GPCho were carried out on three different occasions and the analysis is shown in Supplemental Figure S10. As mentioned in the experimental section, the average variability across each metal, cluster size, and reaction pathway are shown in Supplementary Table S2.

Relative Intensity

$$
=\frac{\% \text { Equation }(X)}{\sum(\% \text { Charge Reduction }+\% \text { Equation }(6-8))}
$$

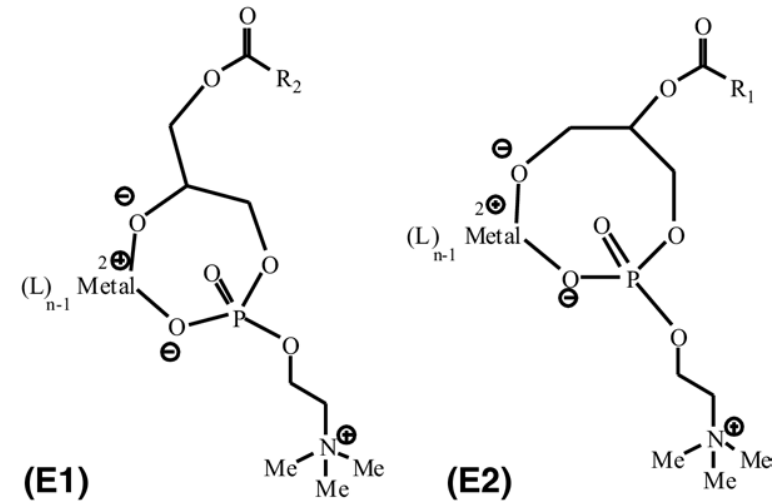

Interestingly, for charge reduction there is a clear trend observed in the $\left[\mathrm{Cu}^{\mathrm{II}}(6: 0 / 6: 0 \mathrm{GPCho})_{n}\right]^{2+}$ spectra (Figure $3 a)$ and $\left[\mathrm{Ca}^{\mathrm{II}}(16: 0 / 18: 1 \mathrm{GPCho})_{n}\right]^{2+}$ and $\left[\mathrm{Mg}^{\mathrm{II}}(16: 0 / 18\right.$ : $\left.1 \mathrm{GPCho})_{n}\right]^{2+}$ spectra (Figure $3 \mathrm{~b}$ ). Thus, as the complexes decrease in size, fewer ions corresponding to the charge-reduced complex are observed. However, for the $\left[\mathrm{Cu}^{\mathrm{II}}(16: 0 / 18: 1 \mathrm{GPCho})_{n}\right]^{2+}$ and $\left[\mathrm{Co}^{\mathrm{II}}(16: 0 / 18\right.$ : $\left.1 \mathrm{GPCho})_{n}\right]^{2+}$ spectra, there is little change in the intensity of this charge-reduced product. Overall, these results seem to track with the second ionization energies (IE2) of the bare metal ions: $\mathrm{Cu}^{2+}(20.3 \mathrm{eV})>\mathrm{Co}^{2+}(17.1$ $\mathrm{eV})>\mathrm{Mg}^{2+}(15.0 \mathrm{eV})>\mathrm{Ca}^{2+}(11.9 \mathrm{eV})$ [13]. Thus the two metals with the highest IE2 $(\mathrm{Cu}$ and $\mathrm{Co})$ appear to stabilize the charge-reduced complexes, most likely via a change in the oxidation state of the metal to yield the charge-reduced complexes. Another possibility is that structural changes caused by the electron capture, particularly in 6:0/6:0GPCho, may lead to increased stability by altering the coordination geometry of the larger complexes $(n=4,5)$. In contrast, complexes composed of the two metals with the lowest IE2 ( $\mathrm{Mg}$ and $\mathrm{Ca}$ ) appear to promote electron capture and fragmentation at the ligand instead of the metal. It is interesting to note the similar behavior in the ECD spectra of metalpeptide complexes [11-13].

\section{Other Trends in the ECD Spectra of the $\left[\operatorname{Metal}^{I I}(L)_{n}\right]^{2+}$ Complexes}

Apart from the direct role of electron capture at the metal center (eq 5 of Scheme 2 and Figure 3a and b) the metal also appears to play a role in the radical fragmentation reactions of the phosphocholine ligand, as highlighted by the data in Figures 3 and 4 . For example, in the case of the $\left[\mathrm{Cu}^{\mathrm{II}}(\mathrm{L})_{n}\right]^{2+}$ and $\left[\mathrm{Co}^{\mathrm{II}}(\mathrm{L})_{n}\right]^{2+}$ complexes, as the size decreases from $n=5$ to $n=2$, the amount of trimethylamine that is lost (eq 7) decreases (Figure 3e, L $=$ 6:0/6:0GPCho; Figure 3f, L = 16:0/18:1GPCho), whereas the amount of methyl radical that is lost (eq 6) increases (Figure 3c, L = 6:0/6:0GPCho; Figure 3d, L = 16:0/18:1GPCho). This result may hint at a change in the coordination properties of the phosphocholine upon fragmentation. Thus loss of a methyl radical from $\mathbf{B}$ unmasks an amine functional group, which may play 
Charge Reduction

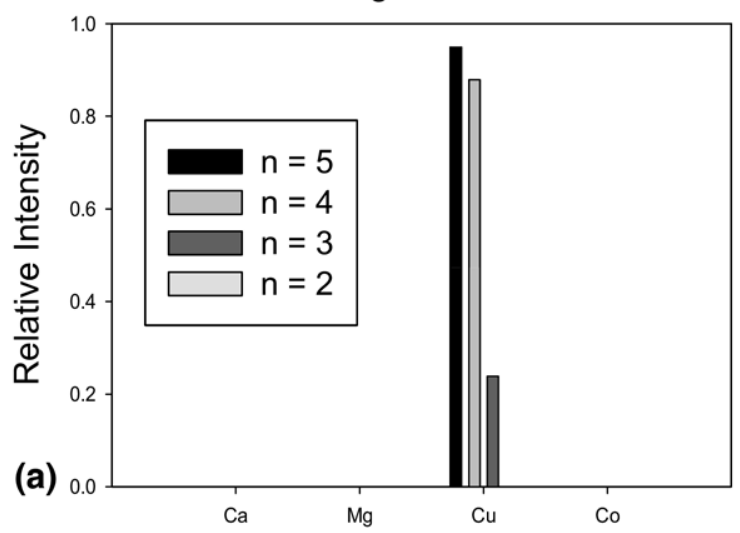

Equation 6
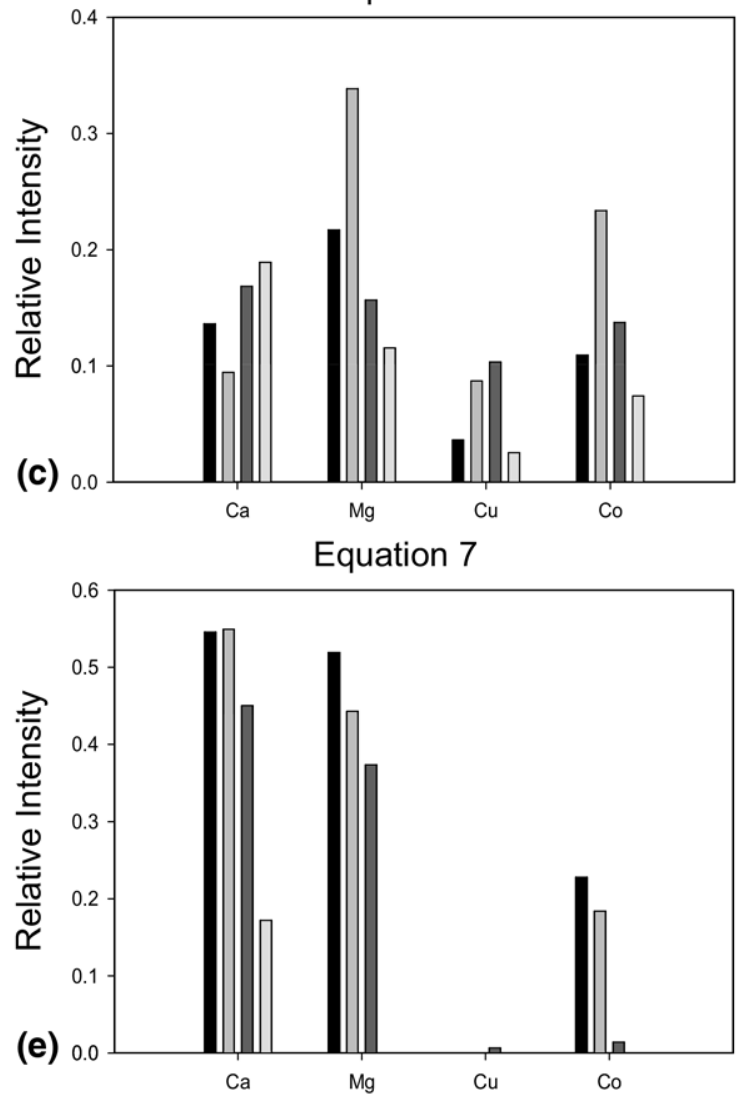

Equation 8

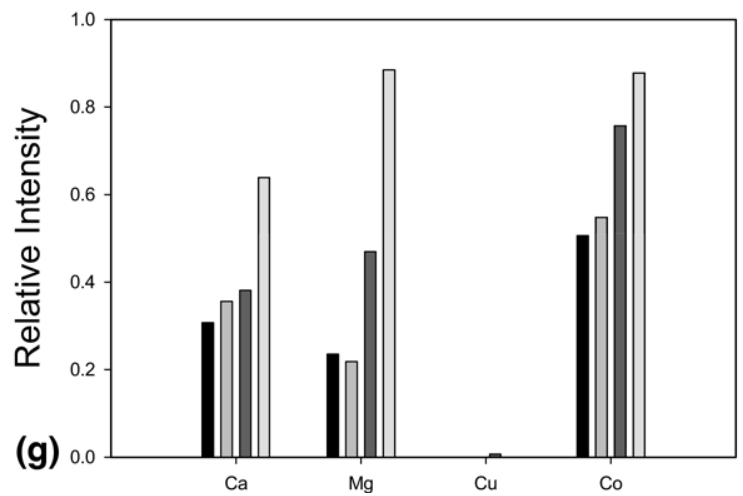

Charge Reduction

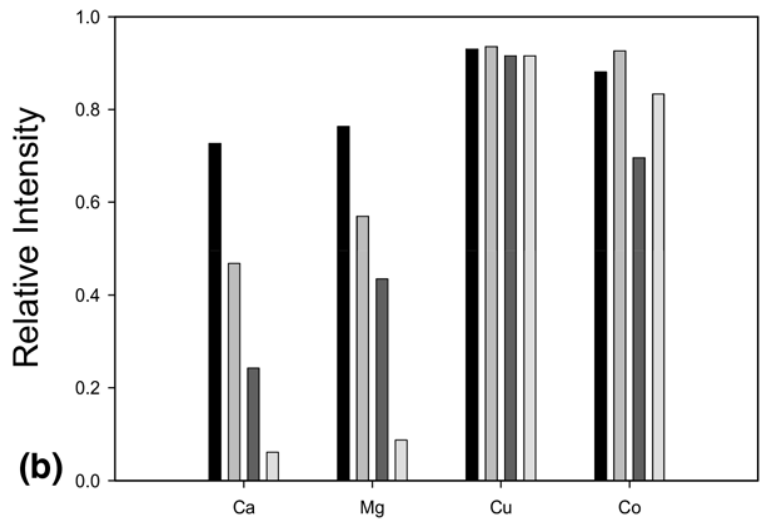

Equation 6

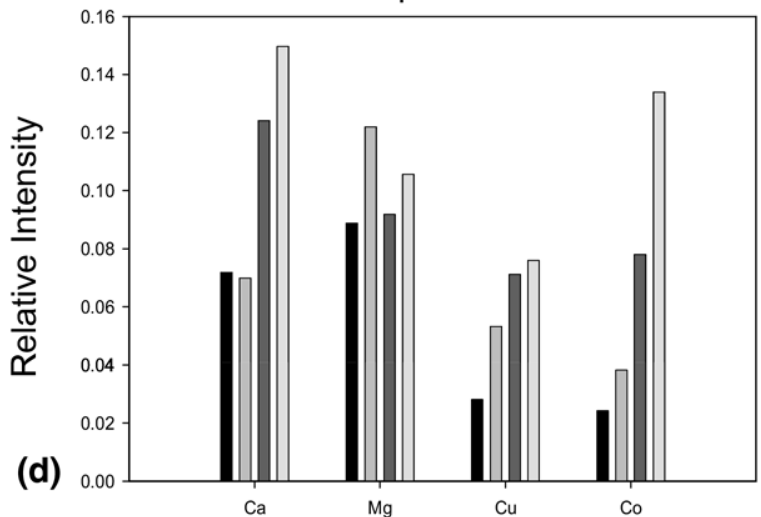

Equation 7

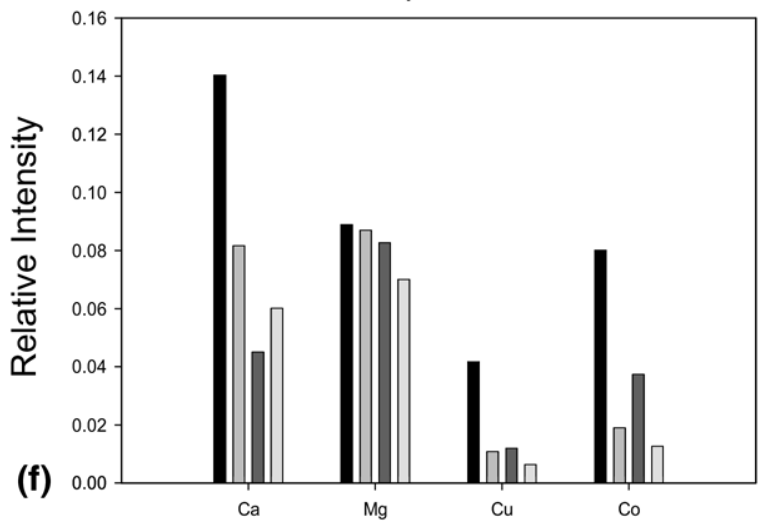

Equation 8

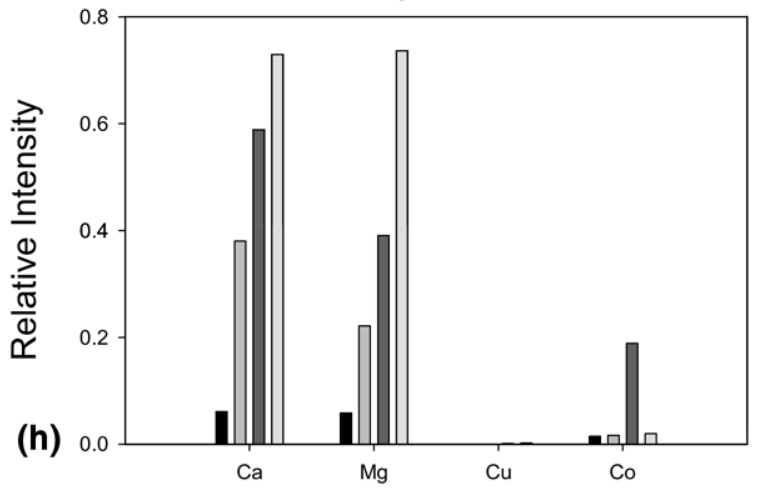



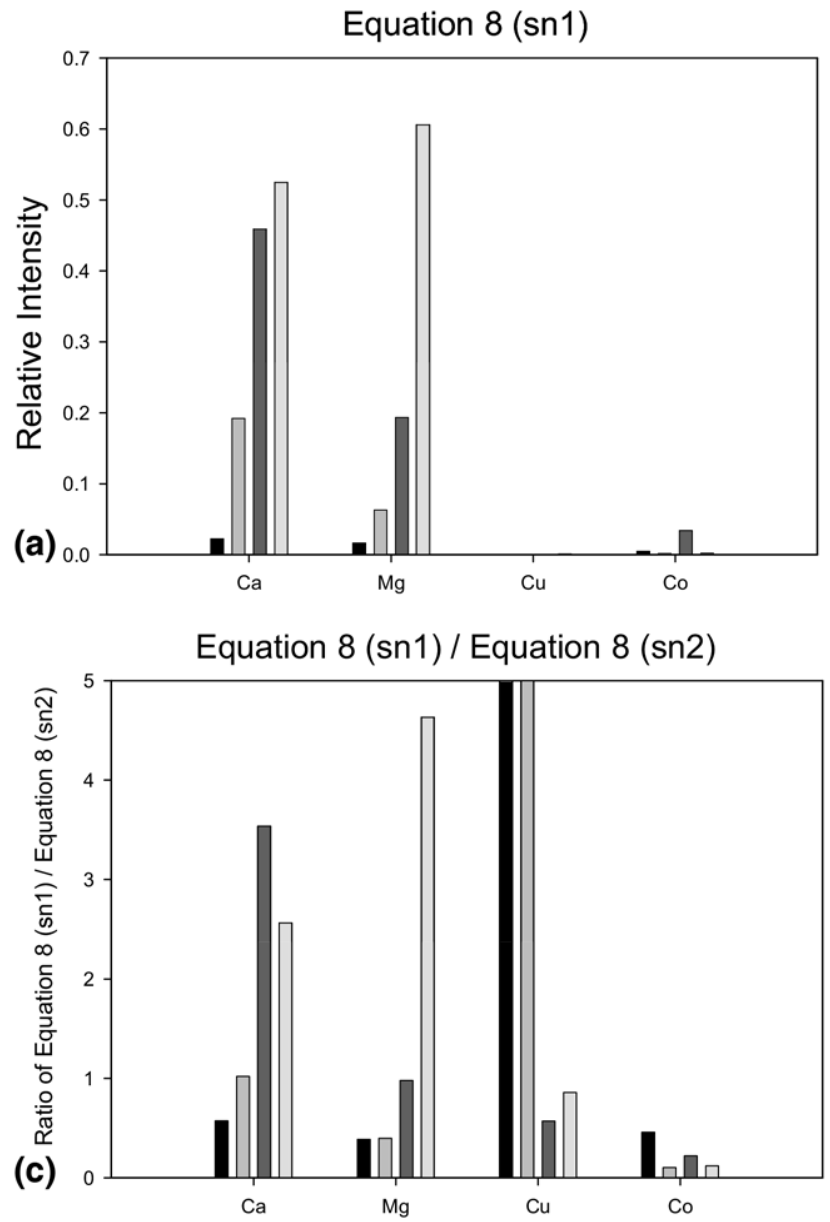

Figure 4. Relative abundances of different product ions observed in the ECD spectra of [Metal ${ }^{\mathrm{II}}$ $\left.(\mathrm{L})_{n}\right]^{2+}$ complexes (where $n=2-5$ and Metal $=\mathrm{Ca}^{2+}, \mathrm{Mg}^{2+}, \mathrm{Cu}^{2+}$, and $\mathrm{Co}^{2+}$ ): (a) loss of the sn1 acyl chain (eq 8 of Scheme 2 ) for $\mathrm{L}=16: 0 / 18: 1 \mathrm{GPCho}$; (b) loss of the sn2 acyl chain (eq 8 of Scheme 2 ) for $\mathrm{L}=16: 0 / 18: 1 \mathrm{GPCho}$; (c) ratio of losses of sn1 and sn2 acyl chains for $\mathrm{L}=16: 0 / 18: 1 \mathrm{GPCho}$; (d) loss of a neutral monomer (eq 5 of Scheme 2 ) for $\mathrm{L}=6: 0 / 6: 0$ GPCho.

an important coordinating role for the $\mathrm{Cu}(\mathrm{II})$ and $\mathrm{Co}(\mathrm{II})$ centers (e.g., to form structures such as F) as the size of the complex gets smaller.

The loss of the acyl groups from the phosphocholines was also investigated (eq 8). First, consider the data shown in Figure $3 \mathrm{~g}$ and $\mathrm{h}$, which sums the losses for both sn1 and sn2 acyl groups. For both 6:0/6:0GPCho (Figure 3g) and 16:0/18:1GPCho (Figure 3h), a systematic increase in the loss of the acyl group for both Ca and $\mathrm{Mg}$ complexes from $n=5$ to $n=2$ is observed. In contrast, loss of the acyl groups is only a minor process for the $\mathrm{Cu}$ complexes and is variable for the Co complexes. Since the acyl groups have different masses in
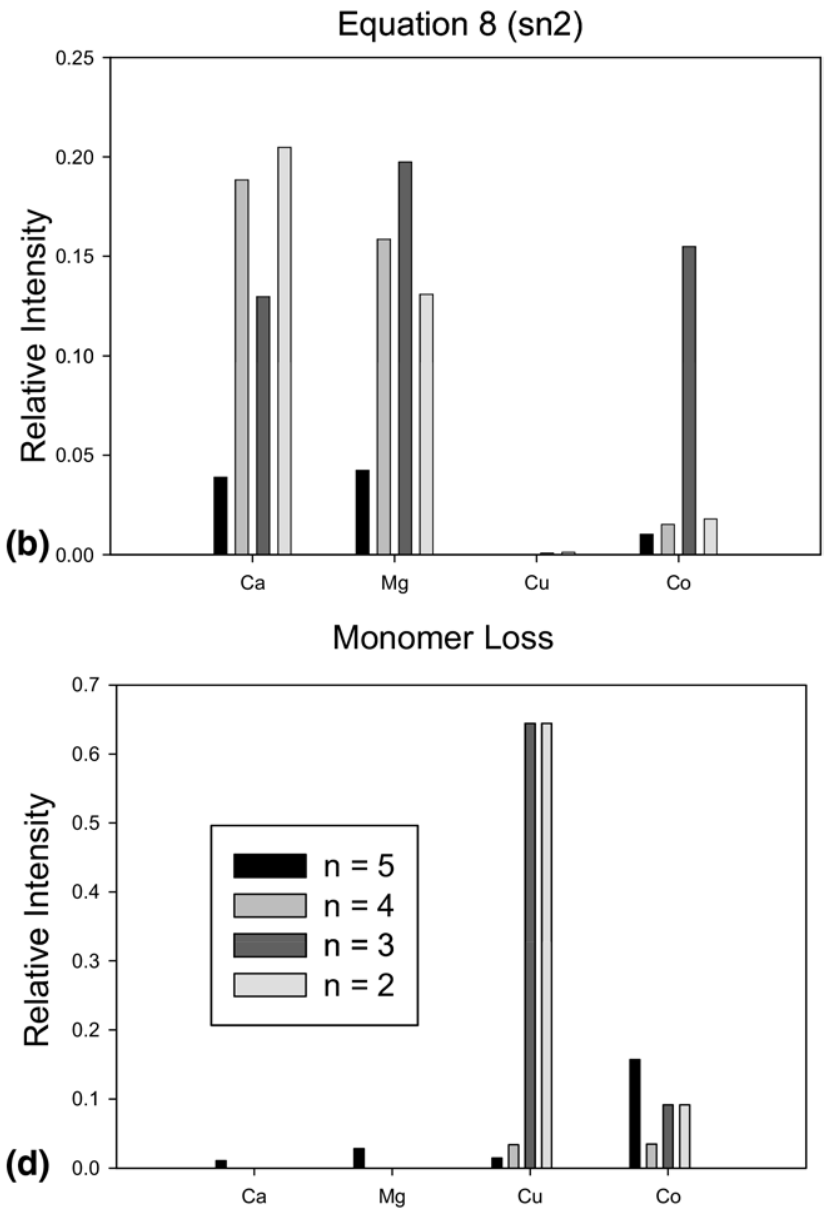

the 16:0/18:1GPCho complexes, it is possible to differentiate losses of the sn1 and sn2 acyl groups for this phospholipid. These data are shown in Figure $4 a$ and $b$. For the loss of the sn1 acyl group, an interesting trend is observed in both the calcium and magnesium spectra, with a distinct increase in the relative intensities as the size of the complex decreases. Not surprisingly, the abundances for the fragment ions are relatively minor for the copper complexes. In the cobalt spectra, although fragment ions for the loss of the sn1 acyl group are observed, there is no clear trend. Furthermore, there is no clear trend for the loss of the sn2 acyl group across the various metals $\left(\mathrm{Ca}^{2+}, \mathrm{Mg}^{2+}, \mathrm{Cu}^{2+}\right.$, and $\left.\mathrm{Co}^{2+}\right)$. In

Figure 3. Relative abundances of different product ions observed in the ECD spectra of $\left[\operatorname{Metal}^{\mathrm{II}}(\mathrm{L})_{n}\right]^{2+}$ complexes (where $n=2-5$ and Metal $=\mathrm{Ca}^{2+}, \mathrm{Mg}^{2+}, \mathrm{Cu}^{2+}$, and $\mathrm{Co}^{2+}$ ): $($ a) charge reduction for $\mathrm{L}=$ 6:0/6:0GPCho; $(\mathbf{b})$ charge reduction for $\mathrm{L}=16: 0 / 18: 1 \mathrm{GPCho}$; (c) loss of Me (eq 6 of Scheme 2) for L = 6:0/6:0GPCho; (d) loss of Me (eq 6 of Scheme 2) for L = 16:0/18:1GPCho; (e) loss of $\mathrm{Me}_{3} \mathrm{~N}$ (eq 7 of Scheme 2) for $\mathrm{L}=6: 0 / 6: 0 \mathrm{GPCho}$; (f) loss of $\mathrm{Me}_{3} \mathrm{~N}$ (eq 7 of Scheme 2) for $\mathrm{L}=$ 16:0/18:1GPCho; (g) loss of the acyl chain (eq 8 of Scheme 2) for L = 6:0/6:0GPCho; (h) loss of the acyl chain (eq 8 of Scheme 2 ) for $\mathrm{L}=16: 0 / 18: 1 G P C h o$. 
<smiles>[R]C(=O)OCC(COP1(=O)OCC[N+](C)(C)[Al]([O])O1)OC([R])=O</smiles>

addition, the ratios of the sn 1 and sn2 intensities of the fragment ions in the ECD spectra for the metal complexes were examined to explore the possibility of preferential losses (Figure 4c). For the calcium and magnesium complexes, there is an obvious difference between the losses of the two acyl groups favoring loss of the sn1 acyl group, with the maximum ratio being observed for the $\left[\mathrm{Mg}^{\mathrm{II}}(16: 0 / 18: 1 \mathrm{GPCho})_{2}\right]^{2+}$ complex (Figure 4c). Although the precise origins of these effects are unclear (as noted earlier, they may relate to subtle coordination effects of the product; see E1 and E2), based on these results it may be possible to determine which acyl group is attached to the sn1 and sn2 positions of an unknown, nonsymmetrical phospholipid by comparing the ECD spectra of its $\mathrm{Ca}^{2+}$ and $\mathrm{Mg}^{2+}$ complexes.

Finally, loss of a neutral phosphocholine ligand (eq $5)$ is important only for the $\left[\mathrm{Cu}^{\mathrm{II}}(6: 0 / 6: 0 \mathrm{GPCho})_{n}\right]^{2+}$ complexes, and increases as the size of the complex decreases (Figure 4d).

\section{Conclusions}

ECD on divalent metal complexes of biologically relevant phospholipids provides structurally diagnostic fragment ions. In particular, ECD provides information on both the identity of the head group [via characteristic losses of $\mathrm{Me}^{\cdot}$ and $\mathrm{N}\left(\mathrm{CH}_{3}\right)_{3}$ ] and the composition of the sn1 and sn2 acyl chains. Although we are unable to directly assign the position of the two acyl chains de novo, we note that certain metals $\left(\mathrm{Ca}^{2+}\right.$ and $\left.\mathrm{Mg}^{2+}\right)$ can be used in conjunction with ECD to correctly assign the structural position of the acyl group based on the preference for the neutral loss of the sn1 fatty acid for the $\left[\operatorname{Metal}^{\mathrm{II}}(\mathrm{L})_{n}\right]^{2+}$ complexes $(n=2,3)$. This result may have implications in the analysis of unknown biological phospholipids, allowing accurate identification of all relevant structural components. Although the position of the double bond cannot be established via ECD on $\left[\mathrm{Metal}^{\mathrm{II}}(\mathrm{L})_{n}\right]^{2+}$ complexes of 16:0/18:1PC, other emerging MS-based approaches such as OzESI show great promise in this area $[14,20]$.

\section{Acknowledgments}

P.F.J. acknowledges the award of an Australian National Heart Foundation Scholarship. M.A.P and R.A.J.O. both thank the Australian Research Council for financial support. An ARC Lief grant and funding from the Victorian Institute for Chemical Sciences are acknowledged for the purchase of the LTQ-FTMS. The authors thank the ARC Centre of Excellence for Free Radical Chemistry and Biotechnology for financial support, Holly Ko for carrying out some preliminary experiments, and the reviewers for their useful comments.

\section{References}

1. Fisher, K. J. Gas-Phase Coordination Chemistry of Transition Metal Ions. Prog. Inorg. Chem. 2001, 50, 343-432.

2. Teesch, L. M.; Adams, J. Metal-Ions as Special Reagents in Analytical Mass Spectrometry. Org. Mass Spectrom. 1992, 27, 931-943.

3. Allison, J. The Gas Phase Chemistry of Transition-Metal Ions in Analytical Mass Spectrometry. Prog. Inorg. Chem. 1986, 34, 627-676.

4. James, P. F.; Perugini, M. A.; O'Hair, R. A. J. Sources of Artefacts in the Electrospray Ionization Mass Spectra of Saturated Diacylglycerophosphocholines: From Condensed Phase Hydrolysis Reactions through to Gas Phase Intercluster Reactions. J. Am. Soc. Mass Spectrom. 2006, 17, 384-394.

5. Pulfer, M.; Murphy, R. C. Electrospray Mass Spectrometry of Phospholipids. Mass Spectrom. Rev. 2003, 22, 332-364.

6. Hsu, F. F.; Turk, J. Electrospray Ionization/Tandem Quadrupole Mass Spectrometric Studies on Phosphatidylcholines: The Fragmentation Processes. J. Am. Soc. Mass Spectrom. 2003, 14, 352-363.

7. Ho, Y. P.; Huang, P. C.; Deng, K. H. Metal Ion Complexes in the Structural Analysis of Phospholipids by Electrospray Ionization Tandem Mass Spectrometry. Rapid Commun. Mass Spectrom. 2003, 17, 114-121.

8. James, P. F.; Perugini, M. A.; O'Hair, R. A. J. Size Matters! Fragmentation Chemistry of $\left[\mathrm{Cu}(\mathrm{L})_{\mathrm{n}}\right]^{2+}$ Complexes of Diacylglycerophosphocholines as a Function of Coordination Number $(\mathrm{n}=2-7)$. Rapid Commun. Mass Spectrom. 2007, 21, 757-763.

9. James, P. F.; Perugini, M. A.; O'Hair, R. A. J. Collision-Induced Dissociation of $\left[\mathrm{Metal}(\mathrm{L})_{2}\right]^{2+}$ Complexes (Metal $=\mathrm{Cu}, \mathrm{Ca}$ and $\mathrm{Mg}$ ) of 1-palmitoyl-2-oleoyl-sn-glycero-3-phosphocholine Allows Distinction of the Acyl Groups at the sn1 and sn2 Positions. Eur. J. Mass Spectrom. 2007, 13, 433-436.

10. Fung, Y. M.; Liu, H.; Chan, T. W. Electron Capture Dissociation of Peptides Metalated with Alkaline-Earth Metal Ions. J. Am. Soc. Mass Spectrom. 2006, 17, 757-771.

11. Kleinnijenhuis, A. J.; Mihalca, R.; Heeren, R. M. A.; Heck, A. J. R. Atypical Behavior in the Electron Capture Induced Dissociation of Biologically Relevant Transition Metal Ion Complexes of the Peptide Hormone Oxytocin. Int. J. Mass Spectrom. 2006, 253, 217-224.

12. Liu, H.; Håkansson, K. Electron Capture Dissociation of Tyrosine O-Sulfated Peptides Complexed with Divalent Metal Cations. Anal. Chem. 2006, 78, 7570-7576.

13. Liu, H.; Håkansson, K. Divalent Metal Ion-Peptide Interactions Probed by Electron Capture Dissociation of Trications. J. Am. Soc. Mass Spectrom. 2006, 17, 1731-1741.

14. Liang, X.; Liu, J.; LeBlanc, Y.; Covey, T.; Ptak, A. C.; Brenna, J. T. McLuckey, S. A. Electron Transfer Dissociation of Doubly Sodiated Glycerophosphocholine Lipids. J. Am. Soc. Mass Spectrom. 2007, 18 1783-1788.

15. Beranova, S.; Wesdemiotis, C. The Unimolecular Chemistry of Quarternary Ammonium-Ions and Their Neutral Counterparts. Int. J. Mass Spectrom. Ion Process. 1994, 134, 83-102.

16. Syrstad, E. A.; Tureček, F. Toward a General Mechanism of Electron Capture Dissociation. J. Am. Soc. Mass Spectrom. 2005, 16, 208-224.

17. Sobczyk, M.; Anusiewicz, W.; Berdys-Kochanska, J.; Sawicka, A.; Skurski, P.; Simons, J. Coulomb-Assisted Dissociative Electron Attachment: Application to a Model Peptide. J. Phys. Chem. A 2005, 109, 250-258.

18. Bowie, J. H. The Formation and Fragmentation of Negative-Ions Derived from Organic-Molecules. Mass Spectrom. Rev. 1984, 3, 161-207.

19. Berger, D. J.; Tank, J. M. Radical Anions and Radical Cations Derived from Compounds Containing C:C, C:O or C:N Groups. In The Chemistry of Double-Bonded Functional Groups; Wiley: Hoboken, NJ, 2003; pp 1281-1354.

20. Thomas, M. C.; Mitchell, T. W.; Blanksby, S. J. Ozonolysis of Phospholipid Double Bonds during Electrospray Ionization: A New Tool for Structure Determination. J. Am. Chem. Soc. 2006, 128, 58-59. 